\title{
Selective proliferation of rat hepatocyte progenitor cells in serum-free culture
}

\author{
Qijie Chen, Junko Kon, Hidekazu Ooe, Kazunori Sasaki \& Toshihiro Mitaka
}

\begin{abstract}
Department of Pathophysiology, Cancer Research Institute, Sapporo Medical University School of Medicine, South-1, West-17, Chuo-Ku, Sapporo 060-8556, Japan. Correspondence should be addressed to T.M. (tmitaka@sapmed.ac.jp).

Published online 10 May 2007; doi:10.1038/nprot.2007.118

This protocol details a method of obtaining selectively proliferated hepatocyte progenitor cells using hyaluronic acid (HA)-coated dishes and serum-free medium. A small hepatocyte (SH) is a hepatocyte progenitor cell of adult livers and has many hepatic functions. When the rat SH begins to proliferate, CD44 is specifically expressed. To define the purification of SH, CD44 and cytokeratin 8 are used as marker proteins. The growth of SHs is faster on HA-coated dishes than on other extracellular matrix-coated ones. The use of both DMEM/F12 medium and HA-coated dishes allows the selective proliferation of SHs in culture. The purification of SHs is approximately $85 \%$ at day 10 .
\end{abstract}

\section{INTRODUCTION}

Small hepatocytes (SHs) are a subpopulation of hepatocytes that have high growth potential in culture ${ }^{1}$. Although the cells are less than half the size of mature hepatocytes (MHs), they possess hepatic characteristics ${ }^{1}$. SHs can clonally proliferate to form a colony and can differentiate into $\mathrm{MHs}$ by interacting with hepatic non-parenchymal cells (NPCs) $)^{2,3}$ or as a result of treatment with gel derived from Engelbreth-Holm-Swarm sarcoma ${ }^{4}$. Thus, we consider that SHs may be 'committed progenitor cells' that can further differentiate into MHs. The standard method to obtain an SH-rich fraction, which is a mixture of SHs and NPCs from a liver cell suspension after collagenase perfusion, has used multistep centrifugation. However, with this method, although SHs account for more than $60 \%$ of the cells at day 10 , it is very difficult to inhibit the growth of NPCs.

Recently, gene expression analysis revealed that CD44 is specifically expressed in SHs but not in $\mathrm{MHs}^{5}$. The CD44 gene encodes for a family of alternatively spliced multifunctional molecules, and CD44 plays a role in adhesion of cells to an extracellular matrix such as hyaluronic acid (HA), collagen (Col) or fibronectin $(\mathrm{FN})^{6}$. CD44 standard form (CD44s) is composed of a short cytoplasmic tail, a transmembrane region and two extracellular domains, and ten variant forms (v1-v10) exist. SHs have been shown to express CD44s and v6 (ref. 5). CD44s in SHs appears from $3 \mathrm{~d}$ after plating; expression increases with the expansion of the SH colony, but decreases with the maturation of SHs. The appearance of CD44v6 is delayed compared with that of CD44s. The expression also disappears with maturation of SHs. Although CD44 is expressed in cultured SHs, no CD44 ${ }^{+}$ hepatocytes are found in the normal rat liver. When the rat liver is severely injured by hepatotoxins such as galactosamine and 2-acetylaminofluorene, $\mathrm{CD} 44^{+}$hepatocytes transiently appear in the periportal regions of the liver lobules. Using an antiCD44 Ab, we have isolated $\mathrm{CD} 44^{+}$cells from the galactosaminetreated rat liver ${ }^{5}$. These $\mathrm{CD}_{4} 4^{+}$cells possess the characteristics of SHs. However, as we were not able to isolate $\mathrm{CD}_{4} 4^{+} \mathrm{SH}$ from either a normal adult liver or from a liver with two-thirds removed, we tested HA as a ligand for separating a population of SHs.
$\mathrm{HA}$, a linear polymer of (1- $\beta-4)$-D-glucuronic acid (1- $\beta-3)-N$ acetyl-D-glucosamine, is a large glycosaminoglycan that can reach a molecular size of $10^{7} \mathrm{Da}$. It is found in the tissue matrix and body fluids of all vertebrates and has diverse biological roles. These include acting as a vital structural component of connective tissues and playing roles in the formation of loose hydrated matrices that allow cells to divide and migrate, immune cell adhesion and activation, and intracellular signaling ${ }^{7}$. Such diversity results from the large number of hyaluronan-binding proteins (termed hyaladherins), which exhibit significant differences in their tissue expression, cellular localization, specificity, affinity and regulation. Three HA synthase (HAS) genes, coding for HAS-1, 2 and 3, are recognized to synthesize $\mathrm{HA}^{8}$. HAS is located at the inner cell membrane, where the newly synthesized HA is extruded into the extracellular space 9 . Synthesized HA is degraded locally in the tissues where it is produced or by the lymph nodes, and the reminder enters the bloodstream ${ }^{10}$. More than $90 \%$ of circulating HA is degraded by hepatic sinusoidal endothelial cells (SECs) through a receptor recycling pathway. Hyaladherins, LYVE-1 and stabilin-1 and 2, but not CD44, are expressed in SEC ${ }^{11,12}$. Furthermore, a relationship between serum HA levels and liver diseases has been reported ${ }^{13}$. HA may be related to the induction of SHs in the liver.

We found that SHs cultured on HA-coated dishes could selectively proliferate to form colonies and that the contamination by NPCs with this method was much less than with our previous method. Although we do not know in detail why a population of SHs can be isolated from a normal liver and selectively proliferate on HA-coated dishes, the HA-CD44 interaction may enhance the growth of SHs. In addition, the combination of DMEM/F12 medium and HA-coated dishes allows us to exclude FBS from the culture. Using this protocol, we have isolated human SHs from a normal adult liver. Taking into consideration the application of hepatic stem/progenitor cells to regenerative medicine, the use of proteins derived from an animal, particularly FBS, should be avoided in the culture of the cells. This protocol for isolating and culturing SHs may help researchers in this field to progress in their own investigations. 
MATERIALS

REAGENTS

- Male F344 rats (Sankyo Lab Service, Tokyo, Japan) weighing 150-200 g ! CAUTION All animal experiments must comply with national and institutional regulations.

- Ascorbic acid-2 phosphate (Asc2P; Wako Pure Chemical Industries, Osaka, Japan, cat. no. 013-12061) (see REAGENT SETUP)

- BSA (30\% solution;Serological Proteins, IL, cat. no. 82-046-3)

- Collagenase (Wako Pure Chemical Industries, cat. no. 034-10533; Yakult

Pharmaceutical Industry, cat. no. YK-101; Sigma, St. Louis, MO, cat. no. C5138)

- Dexamethasone (Wako Pure Chemical Industries, cat. no. 041-18861) (see REAGENT SETUP)

- DMEM/nutrient mixture Ham F-12 (DMEM/F12) (Sigma, cat. no. D8900)

- Nicotinamide-supplemented medium ${ }^{1}$ (to grow MHs)

- L15 medium ${ }^{14}$ supplemented with a growth factor (to grow MHs)

- Epidermal growth factor (EGF; BD Biosciences, Bedford, MA, cat. no.

354001) (see REAGENT SETUP)

-EGTA (Sigma, cat. no. E-0396)

- Gentamicin solution (50 $\mathrm{mg} \mathrm{ml}^{-1}$; Sigma, cat. no. G1397)

- Culture medium stock (see REAGENT SETUP)

- HA derived from human umbilical cords (Biozyme Laboratories, cat. no. HA1NaL), bovine vitreous humor (Sigma, cat no. H7630), pig skin (Seikagaku Kogyo, cat. no. 400720), rooster comb (Sigma, cat. no. H5388) and Streptococcus (Sigma-Aldrich, cat. no. 53747) (see REAGENT SETUP)

- HANKS' balanced salt solution (HANKS; Sigma, cat. no. H9269)

$\cdot 10 \times \mathrm{Ca}^{2+}, \mathrm{Mg}^{2+}$-free HANKS (Sigma, cat. no. H4641)

-Wash solution (see REAGENT SETUP)

- MH wash solution (see REAGENT SETUP)

- Phenol red-free HANKS

- HEPES (Dojindo, Kumamoto, Japan, cat. no. 342-01375)

- Insulin (Sigma, cat. no. I-5500) (see REAGENT SETUP)

-Insulin-transferrin-selenium (ITS; GIBCO, cat. no. 0459)

- $\mathrm{NaHCO}_{3}$ (Kanto Chemical, cat. no. 37116-00)

- Nembutal, $50 \mathrm{mg} \mathrm{ml}^{-1}$ (Dainippon Pharmaceutical, Tokyo, Japan, cat. no. 132141)

- Nicotinamide (Sigma, cat. no. N3376) (see REAGENT SETUP)

- Penicillin-streptomycin solution (Sigma, cat. no. P-4333)

- Percoll PLUS (GE Healthcare Bio-Sciences, Piscataway, NJ, cat. no.

17-5445-01) (see REAGENT SETUP)

- L-Proline (Sigma, cat no. P5607)

- Trypan blue (Chroma Technology, VT, cat. no. 1B187) (see REAGENT SETUP)

-Pre-perfusion solution (see REAGENT SETUP)

EQUIPMENT

-Dishes, 100, 60 and $35 \mathrm{~mm}$ (Corning Glass Works, Corning, NY)

- Non-charged (NC) 60-mm dish (Kord-Valmark, Ontario, Canada, cat. no. 2901)

- Autoclaved 250- $\mu \mathrm{m}$ nylon filter net (Nippon Rikagaku Kikai, Tokyo, Japan)

- Cell strainer, 70- $\mu \mathrm{m}$ filter (BD Falcon, cat. no. REF352350)

-0.2- $\mu \mathrm{m}$ filter (Mediakap-2; Spectrum Laboratories, CA, cat. no.

MEM2M-02B-12S)

- Paper filter no. 3 (Advantec, Tokyo, Japan)

- Sterilized 10-cm Petri dish (glass or plastic)

- Water bath (Teitec Co., Tokyo, Japan, cat. no. EX-B2015250)

- Vascular clamp, bulldog type (Fine Science Tools, Foster City, CA, cat. no. 18050-35)

-Peristatic pump (Tokyo Rika Instruments, Tokyo, Japan, RP-1000)
- Silicon tube $\left(\phi 4.76 \times 7.94 \mathrm{~mm}^{2}\right)$

- Butterfly needle, 18 gauge (Terumo, Osaka, Japan, cat. no. SV-18CLK) - $\mathrm{O}_{2}$ gas $\left(95 \% \mathrm{O}_{2} / 5 \% \mathrm{CO}_{2}\right)$

- Neubauer improved hemocytometer (Sigma, cat. no. Z359629)

\section{REAGENT SETUP}

HA solution Measure flakes or powder of HA; UV irradiate HA on a plastic tray for $1 \mathrm{~h}$. After irradiation, place HA into a 50-ml tube and adjust the concentration of HA stock solution to $10 \mathrm{mg} \mathrm{ml}^{-1}$ by adding sterilized PBS. For UV irradiation, use a standard clean bench or safety cabinet equipped with a UV lamp. ! CAUTION UV is harmful to skin and eyes.

$1,000 \times$ insulin stock solution $\left(500 \mu \mathrm{g} \mathrm{ml}^{-1}\right)$ Add $100 \mathrm{mg}$ insulin to

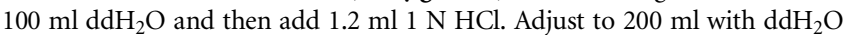
and filter with a $0.2-\mu \mathrm{m}$ filter. $\triangle$ CRITICAL Insulin dissolves in acidic solution.

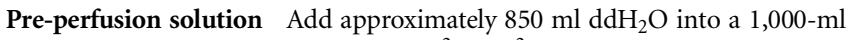
graduated cylinder; add $100 \mathrm{ml} 10 \times \mathrm{Ca}^{2+}, \mathrm{Mg}^{2+}$-free HANKS, $190 \mathrm{mg}$ EGTA,

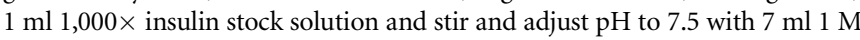
$\mathrm{NaHCO}_{3}$. Adjust to $1,000 \mathrm{ml}$ and filter with a $0.2-\mu \mathrm{m}$ filter. Distribute into each bottle $(150 \mathrm{ml})$. Store at $4{ }^{\circ} \mathrm{C}$ until use. $\triangle$ CRITICAL EGTA solution should be warmed to $37^{\circ} \mathrm{C}$ before use.

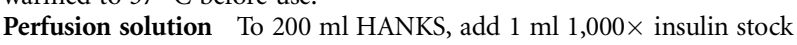
solution and collagenase $\left(100 \mathrm{U} \mathrm{ml}^{-1}\right)$. Shake gently. $\Delta$ CRITICAL Prepare HANKS with insulin before the experiment. Add collagenase to pre-warmed perfusion solution just before use and immediately dissolve by gentle shaking.

Wash solution To $500 \mathrm{ml}$ HANKS, add $0.5 \mathrm{ml} 1,000 \times$ insulin stock solution, $2 \mathrm{ml}$ penicillin-streptomycin solution and $0.5 \mathrm{ml}$ gentamicin solution. MH wash solution To $500 \mathrm{ml}$ HANKS, add $0.5 \mathrm{ml} 1,000 \times$ insulin stock solution, $3.3 \mathrm{ml} \mathrm{BSA}, 2 \mathrm{ml}$ penicillin-streptomycin solution and $0.5 \mathrm{ml}$ gentamicin solution.

Percoll solution ${ }^{15}$ Add $2.4 \mathrm{ml} \mathrm{10 \times} \mathrm{HANKS} \mathrm{and} 21.6 \mathrm{ml}$ Percoll into a 50-ml conical tube. Mix gently upside down several times. Store at $4{ }^{\circ} \mathrm{C}$ until use.

Trypan blue stock solution (0.1\%) Add $100 \mathrm{mg}$ trypan blue to $100 \mathrm{ml}$ phenol red-free HANKS. Filter with a paper filter.

Dexamethasone stock solution Add $39.2 \mathrm{mg}$ dexamethasone to an autoclaved brown bottle. Add $10 \mathrm{ml}$ ethanol ( $10^{-2} \mathrm{M}$ stock solution); dilute to $100 \times$ $\left(10^{-4} \mathrm{M}\right)$ with autoclaved $\mathrm{ddH}_{2} \mathrm{O}$. Store at $4{ }^{\circ} \mathrm{C}$ until use. $\triangle$ CRITICAL $10^{-4} \mathrm{M}$ stock solution must be used within 3 months.

EGF stock solution $\left(\mathbf{1 0} \boldsymbol{\mu} \mathbf{~ m l}^{-1}\right)$ Add $10 \mathrm{ml}$ autoclaved $\mathrm{ddH}_{2} \mathrm{O}$ to an EGF vial. Store 1-ml aliquots in microcentrifuge tubes at $-20{ }^{\circ} \mathrm{C}$ until use.

Nicotinamide stock solution (1M) Add 12.21 g nicotinamide to $100 \mathrm{ml}$ PBS. Filter with a $0.2-\mu \mathrm{m}$ filter and store at $4{ }^{\circ} \mathrm{C}$ until use.

Asc2P stock solution $(100 \mathrm{mM})$ Add $2.90 \mathrm{~g}$ Asc2P to $100 \mathrm{ml}$ PBS, filter with a $0.22-\mu \mathrm{m}$ filter and store at $4{ }^{\circ} \mathrm{C}$ in a $100-\mathrm{ml}$ brown bottle until use.

Culture medium stock Add the following reagents to a 1,000-ml beaker:

DMEM/F12 (15.56 g), HEPES (1.20 g), L-Proline (30 mg), penicillin-streptomycin $(8 \mathrm{ml}), \mathrm{ddH}_{2} \mathrm{O}$ up to $1,000 \mathrm{ml}$. Mix using a magnetic stir bar, add $2.20 \mathrm{~g}$ $\mathrm{NaHCO}_{3}$, adjust $\mathrm{pH}$ to 7.6 with $1 \mathrm{~N} \mathrm{NaOH}$ and filter with a $0.2-\mu \mathrm{m}$ filter.

Store at $4{ }^{\circ} \mathrm{C}$ until use.

Preparation of culture medium Mix DMEM/F12 stock medium (500 ml), BSA $(1.67 \mathrm{ml})$, nicotinamide stock solution $(5.50 \mathrm{ml})$, Asc2P stock solution $(5 \mathrm{ml})$, ITS $(5 \mathrm{ml})$, EGF stock solution $(0.5 \mathrm{ml})$, dexamethasone stock solution $(0.5 \mathrm{ml})$ and gentamicin $(0.5 \mathrm{ml})$.

EQUIPMENT SETUP

Perfusion system See Figure 1a. The system is composed of a water bath, vascular clamp, peristatic pump, silicon tube $\left(\phi 4.76 \times 7.94 \mathrm{~mm}^{2}\right)$ and 18 -gauge butterfly needle.

\section{PROCEDURE}

\section{Preparation of HA-coated dishes TIMING At least $1 \mathbf{d}$ before the experiment}

1) Dilute the stock HA solution to $100 \mu \mathrm{g} \mathrm{cm}^{-2}$ with PBS, fill Petri dishes and incubate at $37{ }^{\circ} \mathrm{C}$ overnight. The next day, discard the solution and wash once with PBS. Aspirate PBS and leave to dry on a clean bench with UV irradiation for 30 min. ! CAUTION UV is harmful to skin and eyes.

\section{? TROUBLESHOOTING}

\section{Isolation of liver cells $\bigcirc$ TIMING 1-1.5 $\mathrm{h}$}

2| Settle the perfusion apparatus in the warmed water bath (Fig. 1a). Pour the pre-perfusion solution into the apparatus before the experiment and bubble it with $95 \% \mathrm{O}_{2} / 5 \% \mathrm{CO}_{2}$ gas at a flow rate of $0.5 \mathrm{I} \mathrm{min}^{-1}$. 
$\triangle$ CRITICAL STEP The equipment should not be left for more than 30 min before proceeding to the next step.

\section{? TROUBLESHOOTING}

3) After light anesthesia by ether, anesthetize a rat with an i.p. injection of nembutal $(5 \mathrm{mg}$ per $0.1 \mathrm{ml}$ per $100 \mathrm{~g}$ body weight).

\section{? TROUBLESHOOTING}

4| Cut the abdominal wall using surgical scissors and open the abdominal cavity to look at the portal vein.

5| Ligate a common bile duct and splenic vein together using a surgical thread at the portion nearest the portal vein (Fig. 1b).

\section{$\triangle$ CRITICAL STEP This is to avoid loss of the solution.}

\section{? TROUBLESHOOTING}

6| Insert a butterfly needle filled with pre-perfusion solution into the portal vein $1.5-2.0 \mathrm{~cm}$ from the bifurcation of the portal vein, stop the tip of the needle at a position close to the bifurcation of the portal vein and clamp the needle with a surgical clip (Fig. 1b).

\section{? TROUBLESHOOTING}

7| Start the perfusion at a flow rate of $30 \mathrm{ml} \mathrm{min}^{-1}$.

8| Cut the inferior vena cava and heart as soon as the flow starts.

$\triangle$ CRITICAL STEP Cut the inferior vena cava at the portion beneath the right kidney and the thoracic cavity, and then cut the heart to flow the perfusate out of the cadaver. Washing out the blood completely from the liver and preventing an increase of intra-hepatic pressure is important to the success of the preparation.

? TROUBLESHOOTING

9| When the amount of the pre-perfusion solution becomes small, add collagenase to the perfusion solution and then pour it into the perfusion apparatus.

$\triangle$ CRITICAL STEP To avoid a decrease in collagenase activity, dissolve it after the pre-perfusion solution flows. Do not mix vigorously.

\section{? TROUBLESHOOTING}

10| Flow the solution at a flow rate $15-20 \mathrm{ml} \mathrm{min}-1$.

$\triangle$ CRITICAL STEP The flow rate should be decided by rat body weight.

? TROUBLESHOOTING

11 Stop the flow before air bubbles move into the liver when the solution flows out from the reservoir.

? TROUBLESHOOTING

12| Cut the liver from the abdominal cavity and transfer it to a sterilized Petri dish.

13| Prepare a $100-\mathrm{ml}$ beaker with $70-80 \mathrm{ml}$ wash solution and add a small amount of the wash solution to the Petri dish.

$\triangle$ CRITICAL STEP From this step onward, all procedures should be done in sterilized conditions.

14| Peel the hepatic capsule as carefully as possible and, to drop the digested cells, shake the liver into the beaker.

? TROUBLESHOOTING

15| Filter the cell suspension through a $250-\mu \mathrm{m}$ nylon filter net into a new $100-\mathrm{ml}$ beaker.

16 Filter the cell suspension through a $70-\mu \mathrm{m}$ filter into four $50-\mathrm{ml}$ conical tubes using a $25-\mathrm{ml}$ pipette and then adjust each tube to an equal volume with the wash solution (approximately $40 \mathrm{ml}$ ).

17| Centrifuge the tubes at $50 \mathrm{~g}$ for $1 \mathrm{~min}$ at $4{ }^{\circ} \mathrm{C}$.

? TROUBLESHOOTING 
PROTOCOL

18| Collect supernatants and transfer to new conical tubes. Repeat Steps 15-17 a total of 3 times.

$\triangle$ CRITICAL STEP Many SHs are included in the supernatant after low-speed centrifugation. This procedure is carried out to remove the majority of MHs from the cell suspension.

PAUSE POINT Cells in tubes may be kept on ice for 1-3 h. Avoid long-term preservation.

19| If you want to isolate MHs, proceed directly to Step 19B. To isolate SHs, proceed with Step 19A.

\section{(A) Isolation of SHs $\bigcirc$ TIMING 1-1.5 h}

(i) Centrifuge the supernatant at $50 \mathrm{~g}$ for 5 min at $4^{\circ} \mathrm{C}$.

$\triangle$ CRITICAL STEP This procedure is used to remove hematopoietic cells. ? TROUBLESHOOTING

(ii) Discard the supernatant and add $40 \mathrm{ml}$ wash solution to the tubes. ? TROUBLESHOOTING

(iii) Centrifuge at $50 \mathrm{~g}$ for $5 \mathrm{~min}$ at $4{ }^{\circ} \mathrm{C}$ after gentle pipetting to dissociate the cell pellet.

(iv) Add $40 \mathrm{ml}$ wash solution and then centrifuge at $150 \mathrm{~g}$ for $5 \mathrm{~min}$ at $4^{\circ} \mathrm{C}$.

$\triangle$ CRITICAL STEP This procedure is carried out to damage some MHs contained in the suspension. ? TROUBLESHOOTING

(v) Discard the pellet, add $40 \mathrm{ml}$ wash solution and then centrifuge at $150 \mathrm{~g}$ for $5 \mathrm{~min}$ at $4{ }^{\circ} \mathrm{C}$.

(vi) Discard the supernatant, pour $20 \mathrm{ml}$ culture medium into each tube and gather the suspension into two 50-ml conical tubes.

(vii) Centrifuge the suspension at $50 \mathrm{~g}$ for $5 \min$ at $4{ }^{\circ} \mathrm{C}$. ? TROUBLESHOOTING

(viii) Add $10 \mathrm{ml}$ culture medium to each tube and gather the suspension into one tube.

(ix) Add $0.5 \mathrm{ml}$ cell suspension to $1.5 \mathrm{ml}$ trypan blue solution and pipette gently. $\triangle$ CRITICAL STEP Tubes should be on ice.

(x) Count the viable cells as soon as trypan blue is added. For counting, use a Neubauer improved hemocytometer. Count the number of cells with trypan blue-negative nuclei which exist in nine masses. Use this formula to obtain the cell number: the number of viable cells (cells $\left.\mathrm{ml}^{-1}\right)=[$ (number of cells inside nine masses) $/ 9] \times 4 \times 10^{4}$.

$\triangle$ CRITICAL STEP Cells with trypan blue-positive nuclei are dead. Count the number of cells that are smaller than typical MHs and larger than NPCs (15-20 $\mu \mathrm{m}$ in diameter). The overall viability of cells will not be good, but most small cells, including SHs, are viable. As SH colony formation depends on the cell density, the number of viable cells, which have the potential to attach to the dishes, is important in this step.

- PAUSE POINT Cells in tubes may be kept on ice for 1-3 h. Avoid long-term preservation.

(xi) Adjust the concentration of the cells to $1 \times 10^{5}$ cells $\mathrm{ml}^{-1}$ and then seed them on HA-coated dishes.

? TROUBLESHOOTING

(xii) Place dishes in a $5 \% \mathrm{CO}_{2} / 95 \%$ air incubator at $37{ }^{\circ} \mathrm{C}$.

(xiii) Replace the medium with fresh medium after $3 \mathrm{~h}$. $\triangle$ CRITICAL STEP This procedure excludes unattached cells.

(xiv) Renew medium every other day.

$\triangle$ CRITICAL STEP Two times a week is enough when the number of attached cells is small.

(B) Isolation of MHs $\bigcirc$ TIMING 1-1.5 h

(i) Add $20 \mathrm{ml}$ MH wash solution to a pellet in each tube (from Step 17) and gather the suspension into two 50-ml conical tubes.

(ii) Centrifuge the tubes at $50 \mathrm{~g}$ for $1 \mathrm{~min}$ at $4{ }^{\circ} \mathrm{C}$ after gentle pipetting to dissociate the cell pellet.

$\triangle$ CRITICAL STEP As MHs are more labile to a shock-like pipetting or centrifugation than SHs, gentle pipetting is important. ? TROUBLESHOOTING

(iii) Discard the supernatant and add $40 \mathrm{ml}$ MH wash solution to each tube.

(iv) Centrifuge at $50 \mathrm{~g}$ for $1 \mathrm{~min}$ at $4^{\circ} \mathrm{C}$. ? TROUBLESHOOTING

(v) Discard the supernatant and add $25 \mathrm{ml} \mathrm{MH}$ wash solution to each tube.

(vi) Pipette gently to dissociate the cell pellet.

(vii) Pour $25 \mathrm{ml}$ cell suspension into Percoll solution and gently mix (upside down several times).

(viii) Centrifuge at $50 \mathrm{~g}$ for $15 \min$ at $4{ }^{\circ} \mathrm{C}$.

$\triangle$ CRITICAL STEP This step is performed to remove dead MHs. After centrifugation, dead MHs and NPCs float on the solution.

? TROUBLESHOOTING

(ix) Discard the supernatant and add $40 \mathrm{ml}$ MH wash solution to each tube.

(x) Centrifuge the tubes at $50 \mathrm{~g}$ for $1 \mathrm{~min}$ at $4{ }^{\circ} \mathrm{C}$ after gentle pipetting to dissociate the cell pellet. ? TROUBLESHOOTING 
(xi) Discard the supernatant and add $40 \mathrm{ml}$ culture medium to each tube.

(xii) Centrifuge the tubes at $50 \mathrm{~g}$ for $1 \mathrm{~min}$ at $4{ }^{\circ} \mathrm{C}$ after gentle pipetting to dissociate the cell pellet. ? TROUBLESHOOTING

(xiii) Add $20 \mathrm{ml}$ culture medium to each pellet and gather the suspension into one tube.

(xiv) Add $0.5 \mathrm{ml}$ cell suspension to $1.5 \mathrm{ml}$ trypan blue solution and suspend.

(xv) Count the number of viable and dead MHs as described in Step $19 \mathrm{~A}(\mathrm{x})$.

$\triangle$ CRITICAL STEP Keep cells in tubes on ice.

(xvi) Adjust cell density to $2-6 \times 10^{5}$ viable cells $\mathrm{ml}^{-1}$ and then seed the cells on dishes. ? TROUBLESHOOTING

(xvii) Place the dishes in a $5 \% \mathrm{CO}_{2} / 95 \%$ air-incubator at $37{ }^{\circ} \mathrm{C}$.

(xviii) 1-2 h later, replace the medium with fresh medium.

$\triangle$ CRITICAL STEP If researchers need to grow MHs, we suggest using nicotinamide-supplemented medium ${ }^{1}$ or L15 medium ${ }^{14}$ supplemented with a growth factor.

? TROUBLESHOOTING

\section{TIMING}

Steps $2-18$, isolation of liver cells: $1-1.5 \mathrm{~h}$

Steps 19A(i-xiv), isolation of SHs: 1-1.5 h

Steps 19B(i-xviii), isolation of MHs: $1-1.5 \mathrm{~h}$

\section{? TROUBLESHOOTING}

Troubleshooting advice can be found in Table 1.

TABLE 1 | Troubleshooting table.

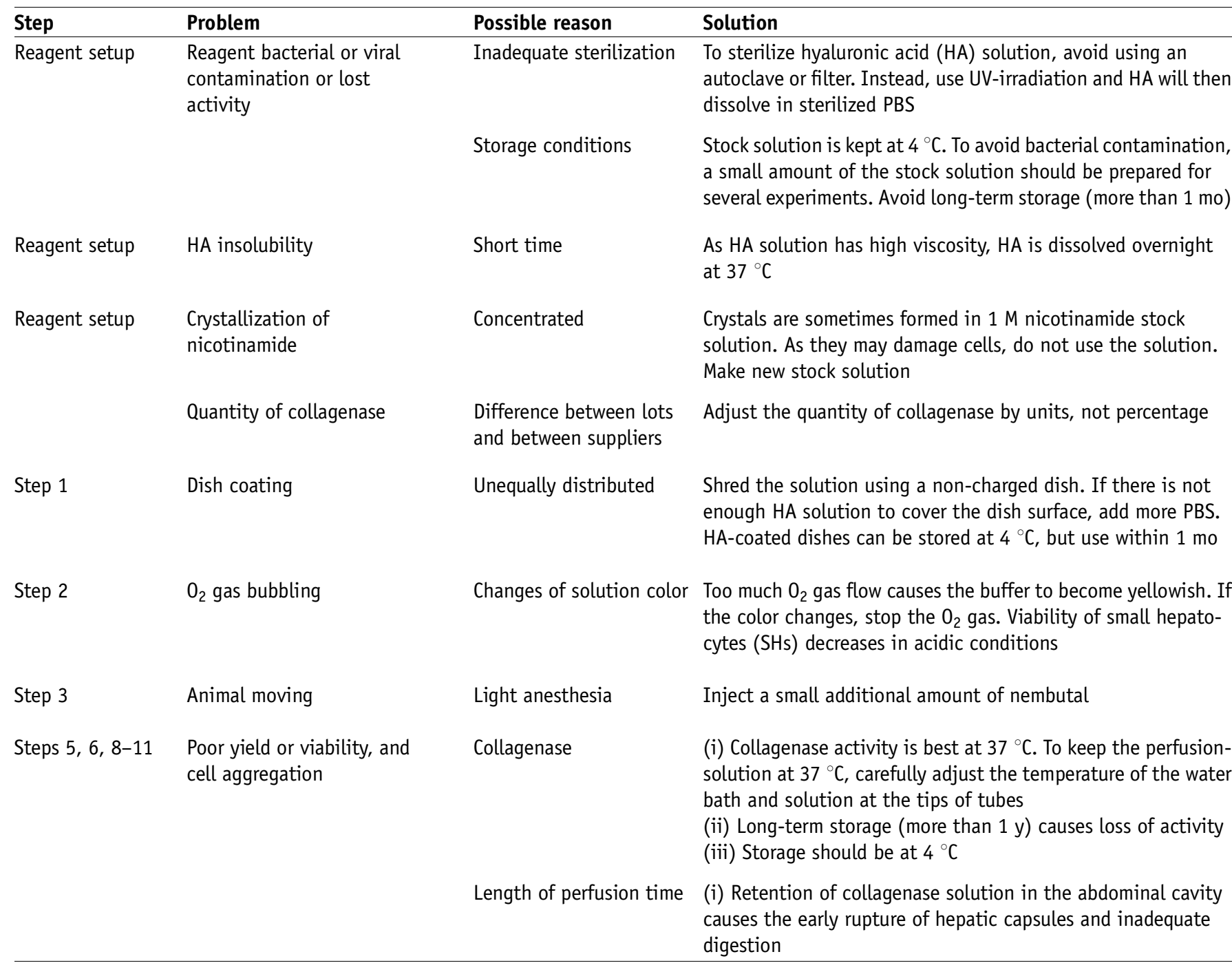


PROTOCOL

TABLE 1 | Troubleshooting table (continued).

\begin{tabular}{|c|c|c|c|}
\hline Step & Problem & Possible reason & Solution \\
\hline & & & $\begin{array}{l}\text { (ii) Although collagenase works efficiently at a slow flow rate, } \\
\text { too slow a flow causes partial perfusion of the liver, and the } \\
\text { yield and viability of the cells have a tendency to be bad }\end{array}$ \\
\hline & & Flow rate & $\begin{array}{l}\text { The flow rate depends on the weight of the rat. When the weight } \\
\text { is more than } 250 \mathrm{~g} \text {, use the maximum flow rate of } 20 \mathrm{ml} \mathrm{min}-1 \text {. } \\
\text { Liver weight is not correlated to body weight in bigger rats. A } \\
\text { relatively high flow rate may cause the early rupture of hepatic } \\
\text { capsules }\end{array}$ \\
\hline & & Embolisms & $\begin{array}{l}\text { (i) Inside of the needle is not filled with perfusate } \\
\text { (ii) Do not shake vigorously after collagenase is added to } \\
\text { perfusion solution } \\
\text { (iii) Tube sometimes generates bubbles and causes air embo- } \\
\text { lisms in the liver. An air-trap apparatus is necessary. A rapid } \\
\text { change of liver color from red-brown to light brown is a sign of } \\
\text { good circulation of the perfusate. Red spots in the liver may } \\
\text { result from embolisms }\end{array}$ \\
\hline
\end{tabular}

Step $14 \quad$ Shortage of cells

Steps 17, 19A(i), Recovery of cells

(ii), (iv) and (vii), 19B(ii), (iv), (viii),

(x) and (xii)

Step $19 A(x i)$

Poor growth of SHs

Step 19B(viii) No pellet

Step 19B(xvi) Poor attachment

Step 19B(xviii) No MH growth
Dish

Insufficient extraction of cells

Time of centrifugation

Few SH colonies

Poor mixture

Too many cells

Few cells

Medium

Growth factors

Water
Centrifugation should be adjusted to $g_{\max }$. The times shown are from pushing the 'Start' button to pushing the 'Stop' button

(i) Avoid plating too small a number of cells. We found that fewer than $2.5 \times 10^{3}$ cells $\mathrm{cm}^{-2}$ resulted in a smaller number of $\mathrm{SH}$ colonies than we expected

(ii) Total number of SH colonies is dependent on rats. Cells from younger rats make many colonies per dish ${ }^{19}$

Mix the cell suspension again and repeat Step 8. Good mixing of cells and Percoll solution is important to obtain high viability and purity of mature hepatocytes (MHs)

$9 \times 10^{5}$ cells and $2 \times 10^{6}$ cells are confluent in $35-\mathrm{mm}$ and 60-mm dishes, respectively

Avoid using fewer than $1 \times 10^{4}$ cells $\mathrm{cm}^{-2}$. MHs need cell-cell contact to survive. Confluence is important to maintain hepatic differentiated functions and cell longevity

In serum-free culture, use extracellular matrix (collagen type I or IV, fibronectin, laminin and vitronectin)-coated dishes. Type I collagen (rat tail collagen) is sufficient for good attachment of MHs. You can also use pre-incubation of serum-supplemented medium for $1 \mathrm{~h}$

(i) Avoid the combination of L15 medium and nicotinamide because many cells may die

(ii) Please refer to review article ${ }^{1}$

Epidermal growth factor, hepatocyte growth factor and transforming growth factor- $\alpha$ have similar growth effects on MHs. $\mathrm{MHs}$ require high-quality water. Water in some places may not be appropriate for the culture even if other cells can grow

Deionization may not solve this problem. We recommend using purchased water; otherwise you can obtain it from a successful laboratory 
a<smiles></smiles>

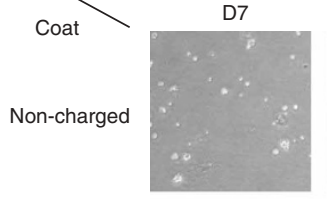
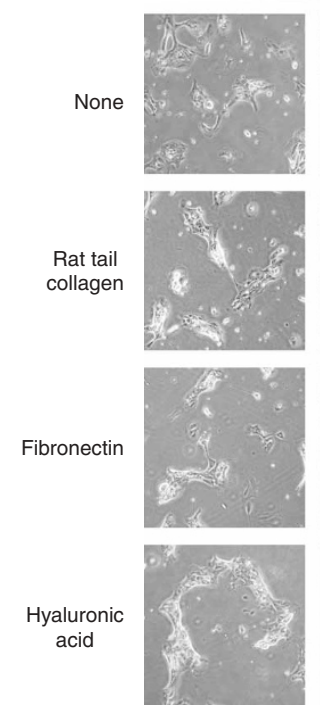

D14
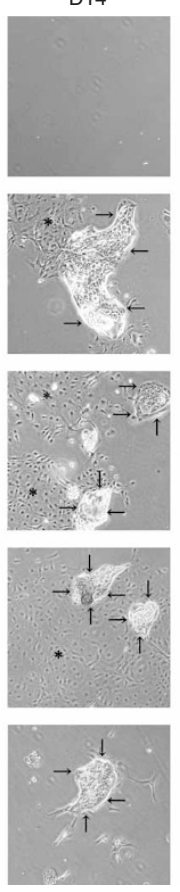

b

D21
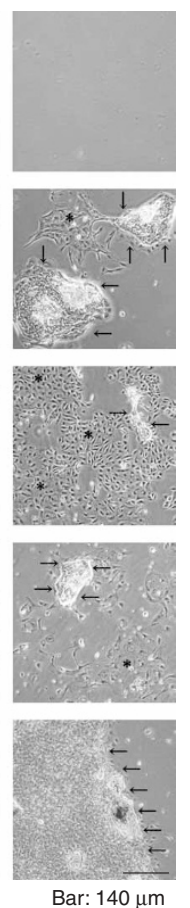

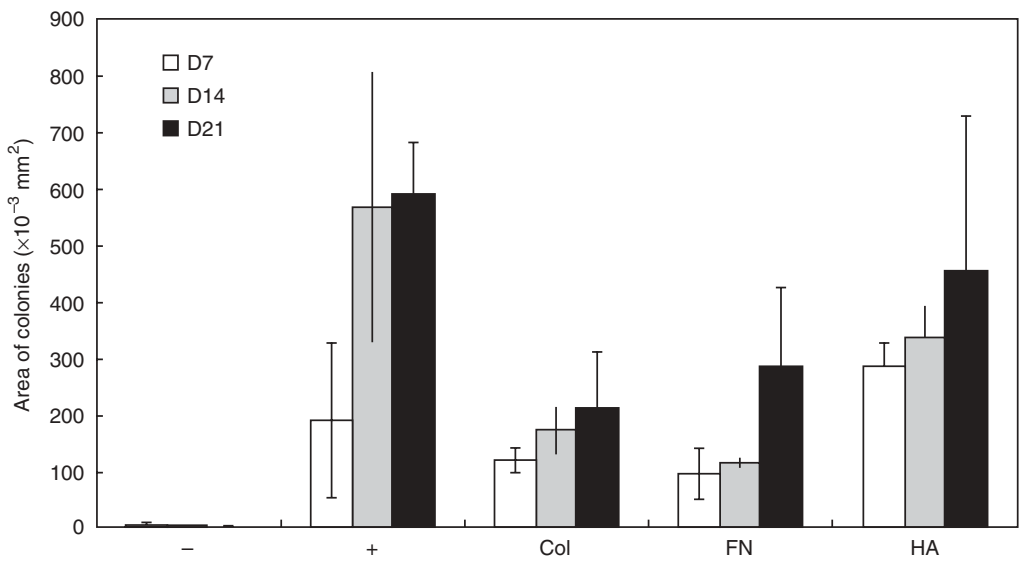

Dish

Figure 2 | Growth of liver cells on dishes coated with extracellular matrices. (a) Phase-contrast micrograph of small hepatocytes (SHs) and non-parenchymal cells at days 7, 14 and 21 after plating. Cells are cultured in DMEM supplemented with 10\% FBS. Arrows show SH colonies and asterisks show NPCs. The expansion of SH colonies is clear and there is little contamination by NPCs on the hyaluronic acid (HA)-coated dish compared with other dishes. At day 21 on HA-coated dishes, proliferated cells, which are marked by arrows, are all SHs. The magnification of the photos is the same; scale bar $=140 \mu \mathrm{m}$. (b) The growth of SH colonies on various dishes. Columns and bars show the average and s.d. of three dishes, respectively.

TABLE 2 | Purity of small hepatocytes cultured in serum-free medium and on hyaluronic acid-coated dishes.

\begin{tabular}{lcc}
\hline Medium & CD44 $^{+}$cells (\%) & CD44- cells (\%) $^{-}$ \\
\hline DMEM/F12-FBS (HA-coated dish) & $84.5 \pm 3.2$ & $15.5 \pm 3.2$ \\
DMEM+FBS (Normal dish) & $64.1 \pm 8.0$ & $35.9 \pm 8.0$ \\
\hline
\end{tabular}

The numbers show the average \pm s.d. of three dishes. Cells were cultured for $10 \mathrm{~d}$ and immunostained for CD44. After counterstaining with hematoxylin, both CD44+ and CD44- cells were counted. CD44- cells include sinusoidal endothelial, stellate, liver epithelial and Kupffer cells.

\section{ANTICIPATED RESULTS}

A critical component of this method is to use HA-coated dishes and serum-free medium for SH culture. As CD44 is not expressed in $\mathrm{MHs}$ but is expressed in $\mathrm{SH}$, we first examined whether $\mathrm{SH}$ s could selectively proliferate on HA-coated dishes under our standard culture conditions

(DMEM $+10 \%$ FBS). As shown in

Figure 2a, compared with the NC-, non-, rat tail Col- and FN-coated dishes, $\mathrm{SH}$ could selectively proliferate on HA-coated dishes. However, there was much less growth of NPCs in HA-coated dishes than in other dishes. The average size of SH colonies on HA-coated dishes was larger than that of $\mathrm{SH}$ colonies on NC-, Col- and FN-coated dishes

(Fig. 2b). Although the SH growth on non-coated dishes was as good as that on HA-coated dishes, NPCs also grew (Table 2).

Next, we examined whether SHs could proliferate in serum-free medium.
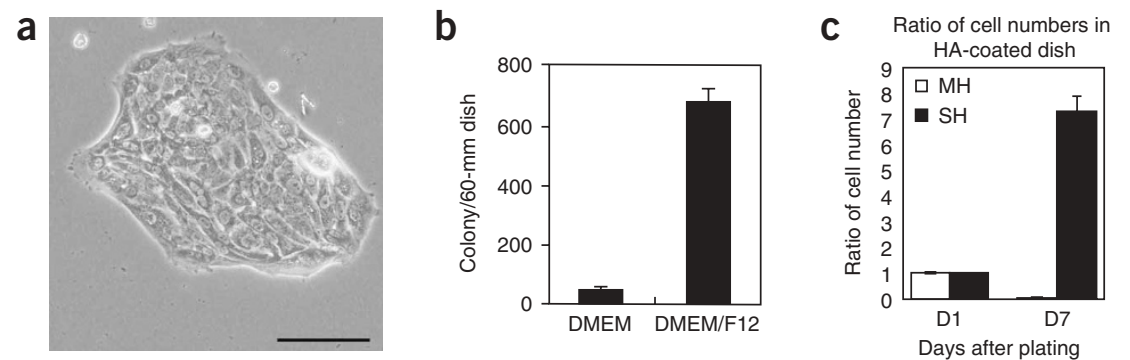

Figure 3 | The growth of small hepatocyte (SH) colonies on hyaluronic acid (HA)-coated dishes cultured in serum-free medium. (a) Phase-contrast micrograph of a typical SH colony at day 7. Scale bar $=$ $100 \mu \mathrm{m}$. (b) The number of SH colonies on HA-coated dishes cultured in serum-free DMEM or DMEM/F12 medium at day 10. Many colonies grew in the serum-free DMEM/F12 medium, whereas there were few in the serum-free DMEM. Columns and bars show the average of the total number of colonies per 60-mm dish and s.d. of three dishes, respectively. (c) Few mature hepatocytes (MHs) can survive in the serum-free medium on HA-coated dishes. The growth of MHs and SHs is shown as the ratio day $7 /$ day 1. 
Although we reported that SH colonies could expand in serumfree medium after re-plating $\mathrm{SH}$ colonies ${ }^{4,16}$, it was very difficult for SHs in serum-free medium to grow to form colonies on conventional dishes. When we used serum-free DMEM/F12 and HA-coated dishes, many colonies developed (Fig. 3a), whereas few colonies grew in serum-free DMEM (Fig. $\mathbf{3 b}$ ). We usually use HA derived from human umbilical cords. However, the effect of HA is not different among commercially available forms of HA derived from pig skin, bovine vitreous humor, rooster comb and Streptococcus (data not shown). To observe the appearance of SHs in serum-free culture, both nicotinamide and growth factors (either a single factor or a combination of EGF, hepatocyte growth factor and transforming growth factor- $\alpha$ ) must be included in the medium ${ }^{1}$. These results suggest that ingredients contained in Ham F12 medium are important for SHs to grow in the serum-free culture, because the use of DMEM alone without FBS cannot support the growth of SHs. However, when the specific agents included in Ham F12 medium were added to DMEM and SHs were cultured in the serum-free medium, the growth of SHs was neither enhanced nor inhibited (data not shown). Therefore, we now hypothesize that the balance of ingredients in Ham F12 medium may be important for SHs to grow in serum-free culture. On the other hand, adding transferrin and selenium is different from the original recipe for culturing rat $\mathrm{SH}^{2}$. Although SHs appear and grow without those agents, both are necessary to maintain their growth in serum-free culture. Without transferrin and selenium, the growth of SHs becomes worse after 1-2 weeks of culture (current data not shown; refer to ref. 1). Figure 3a shows a typical SH colony in serum-free culture. Although it was difficult to avoid MH survival in DMEM with FBS, the use of HA-coated dishes and serum-free medium suppressed MH survival. Most attached MHs died within 1 week (Fig. 3c). In this protocol, the purity of SHs was $84.5 \% \pm 3.2 \%$ at day 10 (Table 2). Some SECs $\left(\mathrm{SE1}^{+}\right)$, stellate cells $\left(\right.$desmin $\left.{ }^{+}\right)$, liver epithelial cells (vimentin ${ }^{+}$) and Kupffer cells $\left(E D 1 / 2^{+}\right)$were observed.

Characterization of SHs on HA was carried out using immunocytochemistry and RT-PCR. All SHs were immunocytochemically stained with anti-CD44 (Fig. 4a) and anti-CK8 Abs (Fig. 4b). As shown in Figure 4c, RT-PCR shows that SHs express mRNAs of hepatic marker genes such as albumin, transferrin, tyrosine aminotransferase, hepatocyte nuclear factor- $4 \alpha$ and CK8 as plentifully as MHs at day 10. In addition, CD44 is not expressed in MHs but is expressed in SHs. These results reveal that cell colonies grown in serum-free DMEM/F12 on HA have quite similar characteristics to SHs observed using our standard culture method (DMEM/FBS). Until now, we have not observed any difference between the cells.

The SH is a hepatocyte progenitor cell that is committed to differentiate into an MH. Manipulation of the growth and maturation of SHs is easy, and they can be cryopreserved ${ }^{17}$. Cryopreserved SHs can maintain the abilities of growth and maturation ${ }^{18}$. Maturated SHs in serum-free culture can be used for studies of hepatic drug metabolism, liver diseases and regenerative medicine.
ACKNOWLEDGMENTS We thank Ms. Yumiko Tsukamoto and Ms. Minako Kuwano for technical assistance. We also thank Mr. K. Barrymore for help with the manuscript. This study was supported by grants from the Science and Technology Incubation Program in Advanced Regions; the Japan Science and Technology Agency; the Ministry of Education, Culture, Sports, Science and Technology, Japan; and the Ministry of Health, Labour and Welfare, Health and Labour Sciences Research Grants, Research on Advanced Medical Technology.

COMPETING INTERESTS STATEMENT The authors declare no competing financial interests.

Published online at http://www.natureprotocols.com

Reprints and permissions information is available online at http://npg.nature.com/ reprintsandpermissions

1. Mitaka, T. The current status of primary hepatocyte culture. Int. J. Exp. Pathol. 79, 393-409 (1998).

2. Mitaka, T., Sato, F., Mizuguchi, T., Yokono, T. \& Mochizuki, Y. Reconstruction of hepatic organoid by rat small hepatocytes and hepatic nonparenchymal cells. Hepatology 29, 111-125 (1999).
3. Sidler Pfändler, M.A., Hochli, M., Inderbitzin, D., Meier, P.J. \& Stieger, B. Small hepatocytes in culture develop polarized transporter expression and differentiation. J. Cell Sci. 117, 4077-4087 (2004).

4. Sugimoto, S. et al. Morphological changes induced by extracellular matrix are correlated with maturation of rat small hepatocytes. J. Cell. Biochem. 87, 16-28 (2002).

5. Kon, J., Ooe, H., Oshima, H., Kikkawa, Y. \& Mitaka, T. Expression of CD44 in rat hepatic progenitor cells. J. Hepatol. 45, 90-98 (2006).

6. Goodison, S., Urquidi, V. \& Tarin, D. CD44 cell adhesion molecules. Mol. Pathol. 52, 189-196 (1999).

7. Stern, R. Hyaluronan catabolism: a new metabolic pathway. Eur. J. Cell Biol. 83 , 317-325 (2004).

8. Weigel, P.H., Hascall, V.C. \& Tammi, M. Hyaluronan synthases. J. Biol. Chem. 272 13997-14000 (1997).

9. Prehm, P. Hyaluronate is synthesized at plasma membranes. Biochem. J. 220, 597-600 (1984).

10. Tengblad, A. et al. Concentration and relative molecular mass of hyaluronate in lymph and blood. Biochem. J. 236, 521-525 (1986). 
11. Mouta Carreira, C. et al. LYVE-1 is not restricted to the lymph vessels: expression in normal liver blood sinusoids and down-regulation in human liver cancer and cirrhosis. Cancer Res. 61, 8079-8084 (2001).

12. Hansen, B. et al. Stabilin-1 and stabilin-2 are both directed into the early endocytic pathway in hepatic sinusoidal endothelium via interactions with clathrin/AP-2, independent of ligand binding. Exp. Cell Res. 303, 160-173 (2005).

13. Saegusa, S., Isaji, S. \& Kawarada, Y. Changes in serum hyaluronic acid levels and expression of CD44 and CD44 mRNA in hepatic sinusoidal endothelial cells after major hepatectomy in cirrhotic rats. World J. Surg. 26, 694-699 (2002).

14. Mitaka, T., Sattler, G.L. \& Pitot, H.C. Amino acid-rich medium (Leibovitz L-15) enhances and prolongs proliferation of primary cultured rat hepatocytes in the absence of serum. J. Cell. Physiol. 147, 495-504 (1991).
15. Kreamer, B.L. et al. Use of a low-speed, isodensity percoll centrifugation method to increase the viability of isolated rat hepatocyte preparations. In Vitro Cell. Dev. Biol. 22, 201-211 (1986).

16. Miyamoto, S., Hirata, K., Sugimoto, S., Harada, K. \& Mitaka, T. Expression of cytochrome $\mathrm{P} 450$ enzymes in hepatic organoid reconstructed by rat small hepatocytes. J. Gastroenterol. Hepatol. 20, 865-872 (2005).

17. Ikeda, S. et al. Proliferation of rat small hepatocytes after long-term cryopreservation. J. Hepatol. 37, 7-14 (2002).

18. Ooe, H. et al. Cytochrome P450 expression of cultured rat small hepatocytes after long-term cryopreservation. Drug Metab. Dispos. 34, 1667-1671 (2006).

19. Mitaka, T., Norioka, K., Sattler, G.L., Pitot, H.C. \& Mochizuki, Y. Effect of age on the formation of small-cell colonies in cultures of primary rat hepatocytes. Cancer Res. 53, 3145-3148 (1993). 